\title{
Results from raw milk microbiological tests do not predict the shelf-life performance of commercially pasteurized fluid milk
}

\author{
N. H. Martin, M. L. Ranieri, S. C. Murphy, R. D. Ralyea, M. Wiedmann, and K. J. Boor ${ }^{1}$ \\ Milk Quality Improvement Program, Department of Food Science, Cornell University, Ithaca, NY 14853
}

\begin{abstract}
Analytical tools that accurately predict the performance of raw milk following its manufacture into commercial food products are of economic interest to the dairy industry. To evaluate the ability of currently applied raw milk microbiological tests to predict the quality of commercially pasteurized fluid milk products, samples of raw milk and $2 \%$ fat pasteurized milk were obtained from 4 New York State fluid milk processors for a 1-yr period. Raw milk samples were examined using a variety of tests commonly applied to raw milk, including somatic cell count, standard plate count, psychrotrophic bacteria count, ropy milk test, coliform count, preliminary incubation count, laboratory pasteurization count, and spore pasteurization count. Differential and selective media were used to identify groups of bacteria present in raw milk. Pasteurized milk samples were held at $6^{\circ} \mathrm{C}$ for $21 \mathrm{~d}$ and evaluated for standard plate count, coliform count, and sensory quality throughout shelf-life. Bacterial isolates from select raw and pasteurized milk tests were identified using $16 \mathrm{~S}$ ribosomal DNA sequencing. Linear regression analysis of raw milk test results versus results reflecting pasteurized milk quality consistently showed low $\mathrm{R}^{2}$ values $(<0.45)$; the majority of $\mathrm{R}^{2}$ values were $<0.25$, indicating small relationship between the results from the raw milk tests and results from tests used to evaluate pasteurized milk quality. Our findings suggest the need for new raw milk tests that measure the specific biological barriers that limit shelf-life and quality of fluid milk products.
\end{abstract}

Key words: preliminary incubation, raw milk, pasteurized milk quality

\section{INTRODUCTION}

One goal of the fluid milk industry in the United States and in several other countries is to extend the shelf-life of HTST-pasteurized milk products (Reneau,

Received October 8, 2010.

Accepted November 20, 2010.

${ }^{1}$ Corresponding author: kjb4@cornell.edu
2007). Post-pasteurization contamination (PPC) - for example, with psychrotolerant Pseudomonas species (Dogan and Boor, 2003) - is currently a major contributor to reduced shelf-life of HTST products. However, in addition to implementation of strategies to prevent PPC in HTST processing plants, to support further extension of HTST product shelf-life, processors also desire tools that will allow them to reliably identify high quality raw milk supplies. Raw milk SCC are inversely related to cheese yield, composition, and quality (Politis and Ng-Kwai-Hang, 1988; Klei et al., 1998), and thereby affect the economics of cheese production. Somatic cell counts are thus a valuable measure of the quality of raw milk used for cheese manufacture. Although raw milk with very high SCC can negatively affect HTST shelf-life during extended storage (Ma et al., 2000; Barbano et al., 2006), the SCC of raw milk in the United States generally does not limit product quality during typical HTST fluid milk shelf-life (i.e., $\leq 21 \mathrm{~d}$ ). Thus, the need exists for tests that can appropriately evaluate raw milk to identify raw milk supplies that allow production of high quality HTST products with incrementally longer shelf-life.

The most commonly used microbiological tests for raw milk quality include the SPC, psychrotrophic bacteria count (PBC), coliform count (CC), laboratory pasteurization count (LPC), direct microscopic count (Laird et al., 2004), and the preliminary incubation (PI) count (Wilson, 2002). For the SPC, a raw milk sample is plated on SPC agar, and then incubated at $32^{\circ} \mathrm{C}$ for $48 \mathrm{~h}$, thereby providing an estimate of total bacteria able to grow under these (aerobic) conditions. Although PBC uses the same growth medium as SPC, incubation occurs at $7^{\circ} \mathrm{C}$ for $10 \mathrm{~d}$; this test thus provides a measure of the initial number of bacteria present that can grow at low temperatures. Coliforms, which can be an indicator of fecal contamination, are enumerated on selective media. For LPC, raw milk is heated at a time-temperature combination that mimics pasteurization, followed by enumeration of bacteria on SPC agar to provide an estimate of the number of bacteria in the raw milk sample that are capable of surviving pasteurization. The PI test is conducted by holding raw milk at $12.8^{\circ} \mathrm{C}\left(55^{\circ} \mathrm{F}\right)$ for $18 \mathrm{~h}$ before performing an $\mathrm{SPC}$. The 
Table 1. Relevant plant specifications and pasteurized milk quality parameters for plants A to D

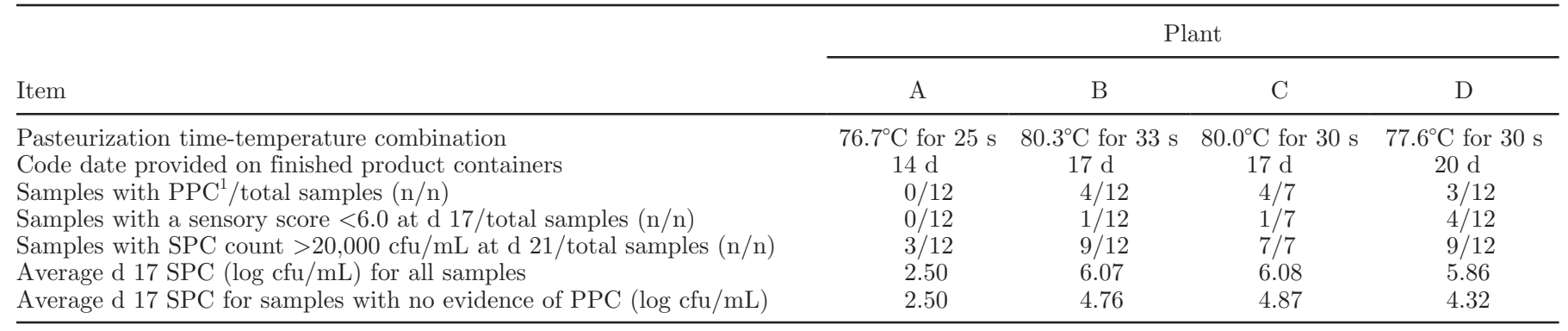

${ }^{1} \mathrm{PPC}=$ post-pasteurization contamination.

PI results are then compared with those from an SPC conducted on the same raw milk sample, or in some cases, the results are compared with a predefined standard. The underlying theory behind the PI test is that bacteria typically associated with a clean, healthy cow (e.g., lactic acid bacteria and Staphylococcus spp.) are not expected to reproduce under PI conditions, whereas other bacterial contaminants that may originate from dirty equipment, the exterior of soiled cows, and so on, may be able to multiply under PI conditions, thus enabling their detection by this test (Murphy, 2008).

The objectives of the present study were to characterize and statistically evaluate relationships between results obtained from a comprehensive set of raw milk tests and the sensory and microbiological characteristics of pasteurized fluid milk manufactured from the tested raw milk. To enable correlation between raw milk quality parameters and quality parameters for commercially produced HTST, which is not feasible when evaluating individual bulk tank samples (except for the rare small processing plants where one commercial processing run uses milk from a single bulk tank), raw milk from plant silos was used in the study. The goal of this study was to enable a scientifically valid selection of raw milk tests that can be used to predict the performance of raw milk in manufacturing high quality HTST fluid milk products.

\section{MATERIALS AND METHODS}

\section{Dairy Plants and Sample Collection}

Both silo raw milk (sampled aseptically from raw milk silos into sterile 500-mL polyethylene terephthalate (Nalgene) bottles (Thermo Fisher Scientific-Nalgene, Rochester, NY) and corresponding pasteurized $2 \%$ fat fluid milk [sampled in 3.8-L (1 gal.) plastic containers] were obtained from 4 fluid milk processing plants in New York State (plants A, B, C, and D, Table 1). Pasteurization time-temperature combinations used for the $2 \%$ fat milk ranged from a low of $76.7^{\circ} \mathrm{C}$ for $25 \mathrm{~s}$ (plant A) to a high of $80.3^{\circ} \mathrm{C}$ for $33 \mathrm{~s}$ (plant B; Table 1 ), indicating that the pasteurized products sampled represented a range of pasteurization conditions.

In each plant, raw and pasteurized milk samples were collected monthly by designated processing plant personnel during 12 consecutive months from October 2007 to September 2008. Three of the plants were sampled once a month for the duration of the study (i.e., $12 \mathrm{mo}$ ), but plant C ceased operation in April 2008; hence, samples from plant $\mathrm{C}$ were only collected for 7 consecutive months. Samples of raw milk were collected immediately before processing, whereas pasteurized samples were collected immediately post-processing; all samples were shipped overnight (on the day of sample collection) to the laboratory in coolers packed on ice. Temperature controls were included in each cooler, and temperature controls were evaluated immediately upon sample arrival at the laboratory; any samples with temperatures $\geq 6^{\circ} \mathrm{C}$ were rejected.

\section{Microbiological Evaluation of Raw Milk}

Upon arrival in the laboratory, each raw milk sample was aseptically distributed into 2 sterile $250-\mathrm{mL}$ glass bottles ( $\sim 100 \mathrm{~mL} /$ bottle) and four $60-\mathrm{mL}$ vials. One $60-\mathrm{mL}$ vial was sent to a commercial laboratory (Dairy One Cooperative, Ithaca, NY) for determination of SCC, and the other aliquots were used to perform a battery of raw milk microbiological tests. Each raw milk sample was tested by spiral plating on (1) Edwards medium (Northeast Laboratory Services, Winslow, ME) for enumeration of Streptococcus spp. (Zadoks et al., 2004); (2) Vogel Johnson (VJ) medium (Quality Milk Production Services, Cornell University, Ithaca, NY) for enumeration of Staphylococcus spp. (Zimbro et al., 2009); and (3) crystal violet tetrazolium agar (CVTA; Difco, BD Diagnostics, Franklin Lakes, NJ) for enumeration of gram-negative organisms (Frank and Yousef, 2004). Further tests performed included (4) SPC, performed by spiral plating raw milk on SPC agar (Difco), followed by incubation at $32^{\circ} \mathrm{C}$ for $48 \mathrm{~h}$ (as described by 
Laird et al., 2004); (5) PBC, performed by spiral plating raw milk on SPC agar (Difco), followed by incubation at $7^{\circ} \mathrm{C}$ for $10 \mathrm{~d}$ (as described by Laird et al., 2004); (6) CC, performed by plating on Petrifilm Coliform Count plates according to manufacturer's instructions (3M, St. Paul, MN); (7) ropy milk test, performed by incubating $25 \mathrm{~mL}$ of each sample at $21^{\circ} \mathrm{C}$ for $48 \mathrm{~h}$ with evaluation for ropiness after both 24 and $48 \mathrm{~h}$; (8) LPC, performed by heating $100 \mathrm{~mL}$ of each sample at $62.8^{\circ} \mathrm{C}$ for $30 \mathrm{~min}$, followed by plating on SPC agar and incubation at $32^{\circ} \mathrm{C}$ for $48 \mathrm{~h}$ (Frank and Yousef, 2004) with the remainder of the LP sample held at $6^{\circ} \mathrm{C}$ and spiral plated on d 7, 10, 14, 17 and 21; (9) spore enumeration (SP), performed by heat treating $100 \mathrm{~mL}$ of sample at $80^{\circ} \mathrm{C}$ for $12 \mathrm{~min}$, followed by spiral plating on SPC agar with the remainder of the SP sample held at $6^{\circ} \mathrm{C}$ and plated on d 7, 10, 14, 17, and 21(Huck et al., 2007a); and (10) PI count, performed by incubating $25 \mathrm{~mL}$ of raw milk at $13^{\circ} \mathrm{C}$ for $18 \mathrm{~h}$, followed by spiral plating on $\mathrm{SPC}$ agar and incubation at $32^{\circ} \mathrm{C}$ for $48 \mathrm{~h}$ (Duncan et al., 2004). The PI count detailed by Duncan et al. (2004) is specifically described as a method for testing pasteurized milk; the method describing PI count for raw milk was removed from Standard Methods for the Examination of Dairy Products after the 15th edition was published in 1985. To further evaluate the groups of bacteria present after PI treatment (i.e., incubation at $13^{\circ} \mathrm{C}$ for $18 \mathrm{~h}$ ), raw milk after PI treatment was also spiral plated on Edwards, VJ, and CVTA media; a 5 -mL aliquot of PI-treated milk was also subjected to the LP test (i.e., laboratory pasteurization at $62.8^{\circ} \mathrm{C}$ for 30 min, followed by spiral plating on SPC agar).

\section{Microbiological and Sensory Evaluations of Pasteurized Milk}

Each pasteurized milk sample was aseptically distributed, after 25 complete inversions of the commercial container, among 4 sterile $500-\mathrm{mL}$ glass bottles (Corning Inc., Corning, NY) (approximately $400 \mathrm{~mL}$ of milk/ bottle), 10 sterile 250 -mL glass bottles (approximately $100 \mathrm{~mL}$ of milk/bottle), and 2 sterile $60-\mathrm{mL}$ vials. One of the $500-\mathrm{mL}$ bottles was used for initial day sensory evaluation, whereas the remaining $500-\mathrm{mL}$ and $250-\mathrm{mL}$ bottles were held at $6^{\circ} \mathrm{C}$ for subsequent sensory testing at $7,10,14$, and $17 \mathrm{~d}$ post-processing and microbiological testing at $7,10,14,17$, and $21 \mathrm{~d}$ post-processing.

Microbiological evaluation of pasteurized milk over shelf-life was performed on the initial day of receipt as well as d 7, 10, 14, 17 and 21 post-processing. Tests performed included (1) SPC (performed as described above for raw milk) and (2) CC, performed on Petrifilm Coliform Count plates (as described for raw milk above).
Pasteurized samples were also evaluated for sensory characteristics on days Initial, 10, 14 and 17. Sensory evaluations were performed in accordance with the guidelines of the American Dairy Science Association as described previously (Bodyfelt et al., 1988); individual scores for a given product were assigned by each member of a trained panel of 6 staff and graduate students from the Cornell University Department of Food Science, and an average acceptability score for each sample was computed from the individual scores. In addition to an acceptability score, the flavor of each sample was described by panelists using predefined sensory attributes (e.g., bitter, fruity fermented, rancid, and unclean). This study was granted exempt status from human subject approval by the Cornell University Committee on Human Subjects. The Compusense Five (version 4.6, Compusense Inc., Guelph, Ontario, Canada) computerized data collection program was used to determine the order of sample presentation and to collect data. Milk samples were mixed by inversion in dim light, capped, and presented to the panelists at $15^{\circ} \mathrm{C}$. Samples were scored on a scale of 1 to 10 , with scores of $<6$ considered "unacceptable."

\section{Isolate Collection and Characterization}

For each sample of raw milk, bacterial isolates were collected from agar plates used for SPC, PBC, and SP, as well as from plates used for selective enumeration of streptococci (i.e., Edwards). In addition, for raw milk samples treated by PI, bacterial isolates were collected from SPC and Edwards plates as well as after LP of PItreated samples. For each sample of raw milk treated by LP or SP, bacterial isolates were collected from samples that reached bacterial counts of $>20,000 \mathrm{cfu} /$ $\mathrm{mL}$ or on the last day of plating (regardless of bacterial counts). For commercially pasteurized $2 \%$ milk, isolates were also collected from samples that showed bacterial counts of $>20,000 \mathrm{cfu} / \mathrm{mL}$ (in the SPC) or on the last day of plating (regardless of bacterial counts). In all cases, colonies representing each visually distinct morphology present (typically 1 to 10 colonies per sample) on the plates described above were selected and streaked for purity on brain-heart infusion agar (Difco). Isolates were frozen at $-80^{\circ} \mathrm{C}$ in $15 \%$ glycerol.

A total of 1,745 isolates were collected over the duration of the study. All isolates obtained from commercially pasteurized milk samples were characterized by sequencing a 616-nucleotide fragment of the $16 \mathrm{~S}$ rRNA gene, performed as described previously (Huck et al., 2007a). The $16 \mathrm{~S}$ sequence data were used to characterize isolates to the genus and species level (where possible), using the RDP database (http://rdp.cme.msu. edu/). Further information on isolates collected in this 
study as well as $16 \mathrm{~S}$ rRNA sequences can be found at www.pathogentracker.net.

\section{Statistical Analysis}

All statistical analyses were performed in JMP (version 7.0, SAS Institute Inc., Cary, NC). Microbiological data were log-transformed before linear regression and coefficient of determination analysis to determine $R^{2}$ values; $R^{2}$ values are a measure of how much of the data can be attributed to, or explained by a linear regression model. An $\mathrm{R}^{2}$ value of 0.0 would indicate that $0 \%$ of the data can be explained by the regression model, whereas an $\mathrm{R}^{2}$ value of 1.0 would indicate that $100 \%$ of the data could be explained by the regression model (Worster et al., 2007). Analysis of variance was performed to determine the effect of raw milk test and plant on measures of pasteurized milk quality.

\section{RESULTS AND DISCUSSION}

Results from the different raw milk tests evaluated here showed very limited correlation among each other, highlighting the fact that distinct microbial populations are targeted by these tests. Limited correlations were also observed between the raw milk microbiological test results and the results from analyses testing the sensory and microbiological quality of the commercially pasteurized, processed milk. Even when PPC was taken into consideration (i.e., by excluding data from 11 samples that showed evidence of such contamination, as well as by analyzing relationships between the microbiological quality of the raw milk samples that had undergone laboratory pasteurization and the results from the corresponding commercial samples), results from raw milk tests did not correlate well with performance of the pasteurized products. We thus conclude that the raw milk tests evaluated in this study have limited utility in predicting the quality of commercial HTST fluid milk.

Statistical relationships among all raw milk parameters used during this study were examined using a scatterplot matrix and $\mathrm{R}^{2}$ values (Supplemental Figure 1, Supplemental Table 1; available online at http:// www.journalofdairyscience.org/). Overall, only 2 pairs of raw milk tests had $\mathrm{R}^{2}$ values $>0.50$; the remainder of the $\mathrm{R}^{2}$ values were low (see Supplemental Table 1 ). The best correlation (i.e., $\mathrm{R}^{2}$ value) between different raw milk tests was between CVTA and PBC results $\left(\mathrm{R}^{2}=\right.$ 0.71). The relatively high correlation between bacterial numbers on CVTA (a medium that discourages growth of gram-positive microbes) and in the PBC test (which selects for organisms that grow at refrigeration temperatures) suggests that gram-negative organisms that may be present in raw milk are capable of growing at refrigeration temperatures. Not surprisingly, the second highest $R^{2}$ value $\left(R^{2}=0.68\right)$ was for PI results on SPC versus results from plating on CVTA after PI. This result indicates that the organisms that grow during the PI also grow well on CVTA. These findings are consistent with data reported by Johns and Landerkin (1969), who concluded that gram-negative rods were the organisms primarily responsible for increased PI counts. The presence of these organisms in raw milk may indicate unsanitary conditions or improper cooling procedures on the farm (Jayarao and Wang, 1999; Murphy, 2008). Although several gram-negative bacteria could be responsible for increased PI counts, the gramnegative Pseudomonas spp. are of particular importance in the dairy industry and have been shown to exist in both the dairy farm environment (Jayarao and Wang, 1999) and in the dairy processing environment (Ralyea et al., 1998; Dogan and Boor, 2003). Some Pseudomonas spp. can produce heat-stable enzymes (e.g., proteases, lipases) that are not inactivated by pasteurization and that can, therefore, affect the sensory quality of the milk post-pasteurization. Sensory problems associated with the presence of Pseudomonas in raw milk are reported to require the presence of bacterial levels higher than the grade "A" raw milk limit (for commingled milk) of 300,000 cfu/mL (Adams et al., 1975; Grieve and Kitchen, 1985). In general, the raw milk samples evaluated here were of high quality (e.g., average SPC of $18,000 \mathrm{cfu} / \mathrm{mL}$, range $3,700-120,000 \mathrm{cfu} / \mathrm{mL}$; average SCC of $220,000 / \mathrm{mL}$, range $160,000-280,000 / \mathrm{mL}$ ). Overall, the low correlations among different raw milk tests were similar to results from a previous study (Boor et al., 1998), which also showed no clear correlation among results from different raw milk microbiological tests conducted on the same sample.

\section{Raw Milk Tests Do Not Predict Microbiological and Sensory Performance and Shelf-Life of Pasteurized Milk}

Somatic cell count and microbiological raw milk test data were evaluated for correlation with different parameters that indicate the quality and shelf-life of the commercially pasteurized $2 \%$ milk, including pasteurized milk SPC at d 17 and d 21 of shelf-life, and sensory scores at d 17 of shelf-life (Table 2, Figure 1). Overall, correlations between different raw milk test results and pasteurized milk quality parameters were low (i.e., all $\mathrm{R}^{2}$ values were $<0.3$ ). Comparison of different raw milk test results to d 17 SPC for pasteurized milk resulted in $\mathrm{R}^{2}$ values ranging from a low of 0.0011 (for VJ), to a high of 0.2416 (for PI count, see Figure 2a). Similarly low $\mathrm{R}^{2}$ values were found from comparing the different raw milk test results to d $21 \mathrm{SPC} ; \mathrm{R}^{2}$ values ranged 
Table 2. Correlation between different raw milk tests and various measures of pasteurized milk quality

\begin{tabular}{|c|c|c|c|c|c|c|c|c|}
\hline $\begin{array}{l}\text { Raw milk } \\
\text { test }^{1}\end{array}$ & \multicolumn{8}{|c|}{ Correlation $\left(\mathrm{R}^{2}\right)^{2}$} \\
\hline SP & 0.0031 & 0.0001 & 0.0000 & 0.0058 & 0.0301 & 0.0223 & 0.0002 & 0.0140 \\
\hline Edwards & 0.0092 & 0.2637 & 0.0002 & 0.2186 & 0.0283 & 0.0212 & 0.0109 & 0.0180 \\
\hline VJ & 0.0011 & 0.0950 & 0.0003 & 0.1274 & 0.0145 & 0.0229 & 0.0569 & 0.0266 \\
\hline $\mathrm{PBC}$ & 0.1280 & 0.2173 & 0.0876 & 0.1228 & 0.0097 & 0.0038 & 0.0601 & $0.0798^{*}$ \\
\hline CVTA & 0.1238 & $0.4169^{*}$ & 0.1125 & $0.3681^{*}$ & 0.0003 & 0.0092 & $0.0907^{*}$ & 0.0678 \\
\hline Coliform & 0.1301 & 0.2641 & 0.1471 & 0.2413 & 0.0565 & 0.0461 & 0.0399 & 0.0064 \\
\hline PI & $0.2416^{*}$ & 0.1973 & $0.2211^{*}$ & 0.1874 & 0.1060 & 0.0725 & 0.0003 & 0.0003 \\
\hline$\Delta \mathrm{PI}$ & 0.1807 & 0.1524 & 0.1554 & 0.1291 & $0.1314^{*}$ & 0.0628 & 0.0436 & 0.0270 \\
\hline
\end{tabular}

${ }^{1} \mathrm{SP}=$ spore pasteurization; Edwards = growth on Edwards medium for enumeration of Streptococcus spp.; VJ = growth on Vogel Johnson medium for enumeration of Staphylococcus spp.; LP = laboratory pasteurization at d 0; PBC = psychrotrophic bacteria count; CVTA = growth on crystal violet tetrazolium agar for enumeration of gram-negative organisms; PI = preliminary incubation; $\Delta \mathrm{PI}=$ change in bacterial numbers from raw SPC to PI.

${ }^{2} \mathrm{R}^{2}$ values were obtained from linear regression models of log-transformed raw milk test data and various measures of pasteurized milk quality; $\mathrm{R}^{2}$ values marked with a * indicate the highest $\mathrm{R}^{2}$ values for a raw milk test associated with each pasteurized milk quality parameter. Pasteurized milk quality parameters included SPC at d 17 and d 21, average sensory score at d 17 and 21 as well as LP counts at d 17 and 21 . For pasteurized milk SPC and sensory scores, $\mathrm{R}^{2}$ values were calculated for all samples or only those samples that showed no evidence for post-pasteurization contamination (PPC).

from a low of 0.0000 (for SP), to a high of 0.2211 (for PI count; Table 2, Figure 2a). When comparing raw milk tests results to pasteurized milk sensory scores (at d 17), correlations were even lower: $\mathrm{R}^{2}$ values ranged from 0.000 to 0.1314 for $\mathrm{d} 17$ sensory scores (Table 2 ). The numerically highest $R^{2}$ value for correlations between raw milk test results and d 17 sensory scores was 0.1314 (for $\Delta$ PI, i.e., the difference between the PI count and the SPC before PI incubation; see Table 2); the $\mathrm{R}^{2}$ value of PI count versus $\mathrm{d} 17$ sensory score was 0.1060 (Table 2, Figure 2b). The ANOVA for each the 10 raw milk tests was also used to determine the effect of the raw milk tests as well as the effect of plant on d 17 SPC and d 17 sensory scores. Of the 10 raw milk tests used, none showed results that were significantly associated with d $17 \mathrm{SPC}$ and d 17 sensory scores (all $P$-values $>0.20$ and $>0.10$, respectively). Conversely, the factor "plant" showed a significant effect $(P<0.05)$ for 6 out of the 10 comparisons for each d 17 SPC as well as d 17 sensory scores. Overall, these initial analyses indicate that none of the raw milk tests (when performed on silo raw milk) show sufficient correlation with pasteurized milk quality to allow for prediction of microbiological or sensory quality and shelf-life of commercially HTST pasteurized fluid milk.

\section{Raw Milk Tests Do Not Predict Pasteurized Milk Performance When PPC Is Controlled}

Because commercially produced HTST fluid milk spoilage is affected by a variety of factors in addition to raw milk quality, most notably PPC, we hypothesized that the poor correlation between raw milk test results and pasteurized milk microbiological and sensory quality measures, which is detailed above, may be due to the fact that some of the pasteurized milk samples tested here showed evidence of PPC (i.e., the presence of large numbers of gram-negative microbes in pasteurized milk). To address this issue, we performed additional analyses that evaluated correlations between different raw milk test results and (1) sensory and microbiological quality of commercial pasteurized milk after excluding pasteurized milk samples that showed evidence of PPC and (2) the microbiological quality of the raw milk samples that had undergone laboratory pasteurization.

Overall, 11 of the 43 samples of pasteurized $2 \%$ milk evaluated here showed evidence for PPC (see Tables 1 and 3). Samples were categorized as having PPC on the basis of the predominant microbes present in the pasteurized product. Overall, 243 bacterial isolates from 43 pasteurized milk samples were characterized with approximately 5 isolates characterized from each sample. The most common genera identified included Bacillus (43 isolates), Paenibacillus (90 isolates), Pseudomonas (55 isolates), other gram-negative organisms (including Acinetobacter spp., Stenotrophomonas spp., and others for a total of 33 isolates), and other gram-positive organisms (including Staphylococcus spp., Streptococcus spp., and others for a total of 22 isolates). Eleven pasteurized milk samples with evidence for microbial spoilage due to PPC showed microbial spoilage profiles that 


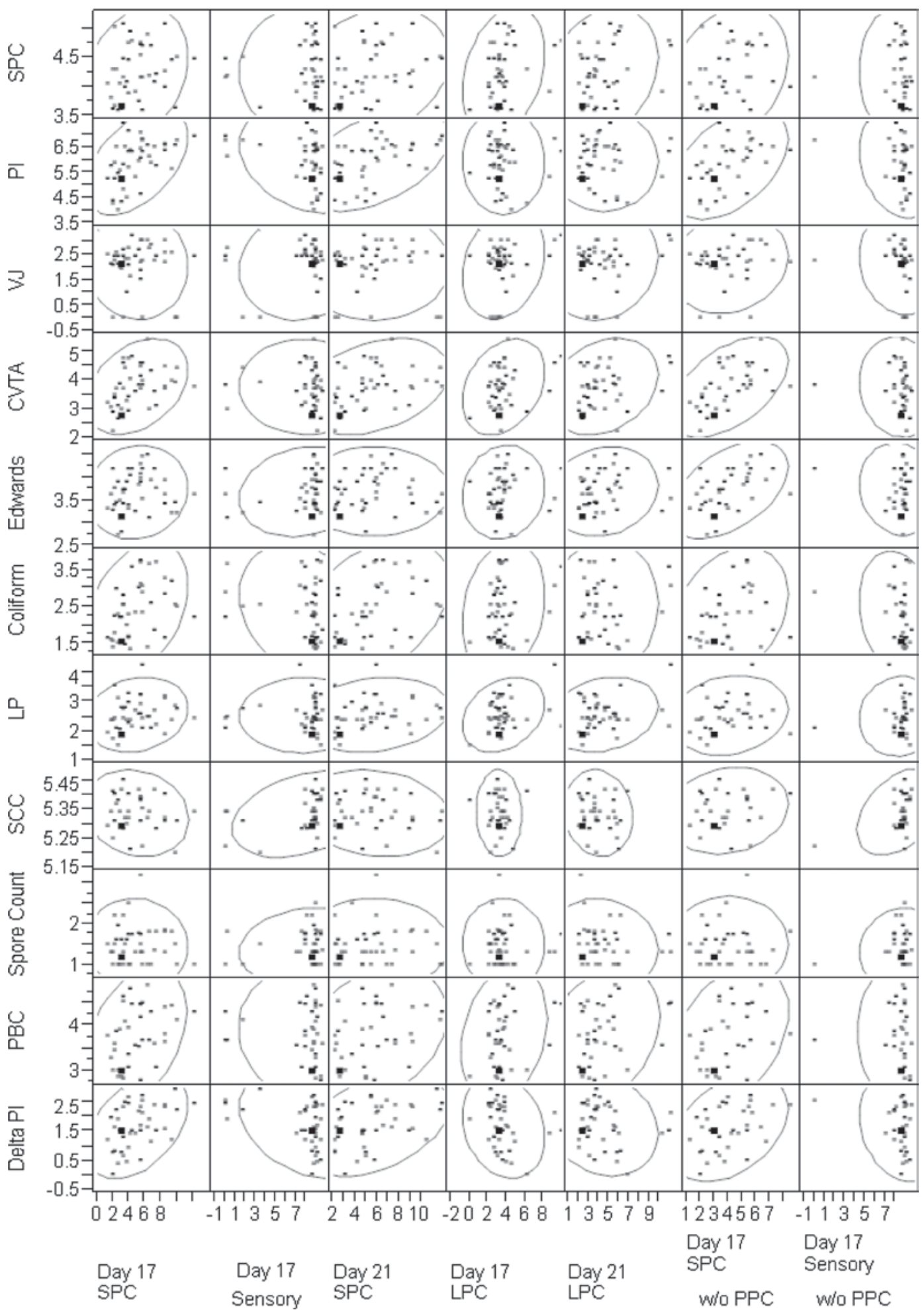

Figure 1. Scatterplot matrix of log-transformed data depicting the relationship between results from raw milk tests and various measures of pasteurized milk quality (data points represent relationships for 43 raw milk and 43 pasteurized milk samples collected from 4 New York State fluid milk processors). Ellipses encompass $95 \%$ of data points. PI = preliminary incubation; VJ = growth on Vogel Johnson medium for enumeration of Staphylococcus spp.; CVTA = growth on crystal violet tetrazolium agar for enumeration of gram-negative organisms; Edwards = growth on Edwards medium for enumeration of Streptococcus spp.; LP = laboratory pasteurization; PBC $=$ psychrotrophic bacteria count; $\Delta \mathrm{PI}$ $=$ change in bacterial numbers from raw SPC to PI; LPC = laboratory pasteurization count; PPC = post-pasteurization contamination. 
A.

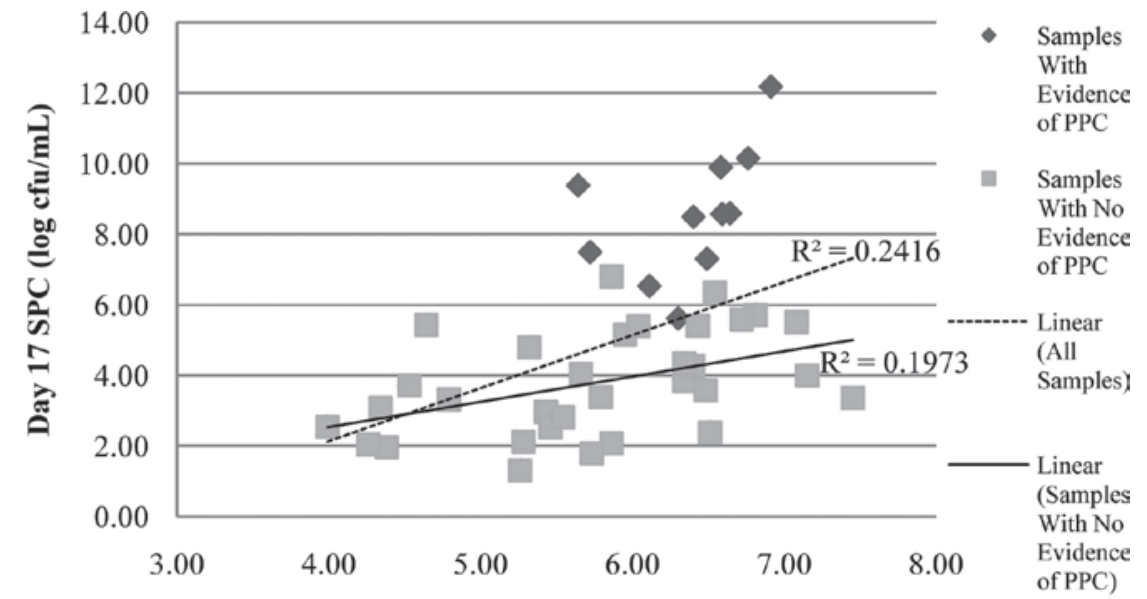

B.

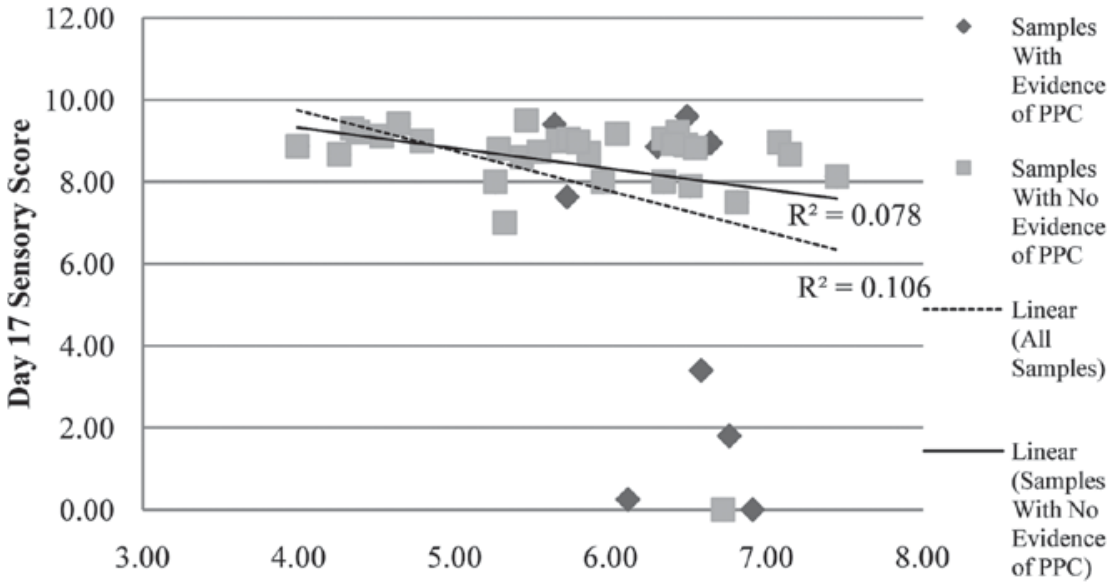

C.

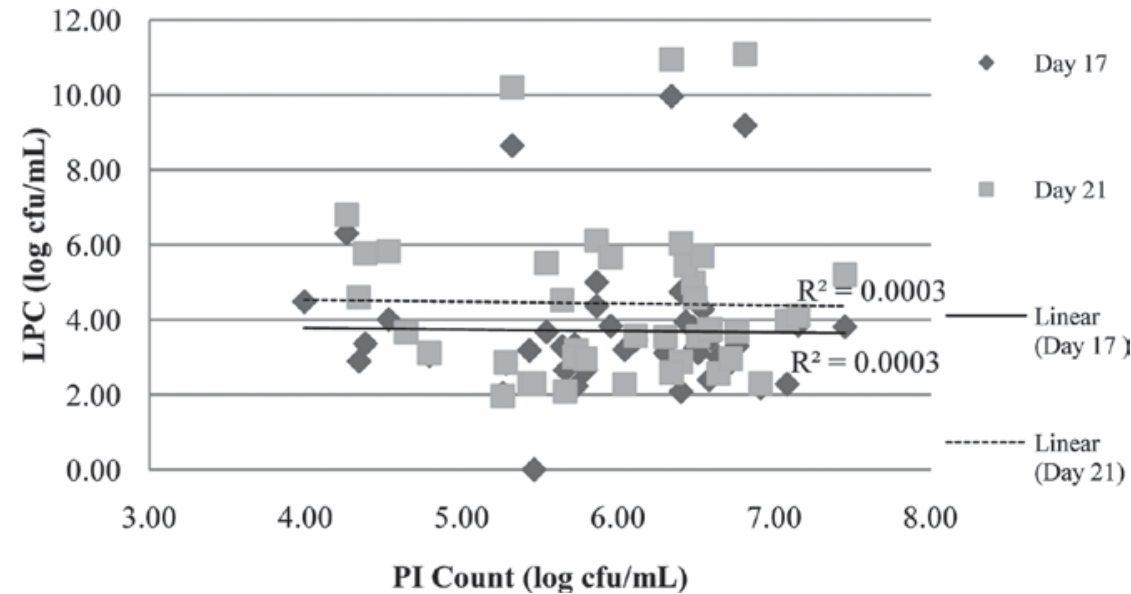

Figure 2. Linear regression analysis of (A) log-transformed d 17 SPC counts of $2 \%$ pasteurized milk versus log-transformed raw milk preliminary incubation (PI) counts; (B) d 17 sensory scores of $2 \%$ pasteurized milk versus log-transformed raw milk PI counts; and (C) log-transformed laboratory pasteurization count (LPC) for d 17 and d 21 versus log-transformed raw milk PI counts. Each point represents data from 1 of 43 samples collected from 4 New York State fluid milk processors. For panels A and B, data for sample pairs where the pasteurized milk sample showed evidence for post-pasteurization contamination (PPC) are shown as black diamonds, whereas sample pairs in which the pasteurized milk sample showed no evidence for PPC are shown as gray squares. In panel B, 4 of the 5 sensory data points represented by black diamonds (1 sample each from plants B and C and 2 samples from plant D) that fell below a score of 6.0 showed evidence for PPC, whereas 1 sample (represented by the gray square, sample from plant D) was characterized by predominance of Bacillus spp. and Paenibacillus spp. and showed no signs of PPC. Linear regression lines for all samples and for only those samples that show no evidence for PPC are also shown in panels A and B. 
were characterized by a predominance of Pseudomonas spp. (and other non-spore-forming spoilage organisms that are not expected to survive HTST pasteurization, e.g., Staphylococcus spp. and Streptococcus spp.; Table $3)$. Four of the 11 samples determined to have PPC had unacceptable sensory scores at d 17 (Table 3); all 11 of the PPC samples had $>20,000 \mathrm{cfu} / \mathrm{mL}$ by d 17 , including 7 samples that had $>20,000 \mathrm{cfu} / \mathrm{mL}$ by $\mathrm{d}$ 10. Microbial profiles of the pasteurized milk samples without evidence for PPC were predominated by the presence of Bacillus spp. and Paenibacillus spp., representing spore-formers that have the ability to survive HTST pasteurization (Collins, 1981). One sample from plant $\mathrm{D}$, where the predominant organisms present at the end of shelf life were determined to be Bacillus spp. and Paenibacillus spp. and which showed no evidence of PPC, had a d 17 sensory score of zero (Table 3, Figure $2 \mathrm{~b}$ ), highlighting the possibility for these organisms to cause sensory defects in fluid milk. To evaluate the ability of raw milk tests to predict the performance of pasteurized milk in the absence of possible confounding effects resulting from inclusion of data for commercially pasteurized milk affected by PPC, we determined correlations (i.e., $\mathrm{R}^{2}$ values) between raw milk test results and corresponding quality and shelf-life parameters for the commercially pasteurized $2 \%$ milk, including SPC at d 17 and d 21 of shelf-life, and sensory scores at d 17 of shelf-life (Table 2, Figure 1), excluding the 11 pasteurized milk samples (and corresponding raw milk data) that showed evidence for PPC. When comparing the different raw milk test results to d 17 SPC counts for pasteurized milk, $\mathrm{R}^{2}$ values ranged from a low of 0.0001 (for SP) to a high of 0.4169 (for CVTA, see Table 2). Similarly, low $\mathrm{R}^{2}$ values were found when comparing the different raw milk test results to $\mathrm{d} 21$ SPC: $\mathrm{R}^{2}$ values ranged from a low of 0.0016 (for SCC) to a high of 0.3681 (for CVTA). The $\mathrm{R}^{2}$ values for raw milk test results versus sensory scores at $\mathrm{d} 17$ were also extremely low, ranging from 0.000 (for raw milk SPC) to 0.1571 (for SCC). The $\mathrm{R}^{2}$ values for PI count results versus d 17 SPC, d 21 SPC, and d 17 sensory scores were all extremely low $(0.1973,0.1874$, and 0.0725 , respectively; see Table 2, Figure 2a,b). Overall, these data further support that the raw milk tests used here (when performed on silo raw milk) do not show sufficient correlation with pasteurized milk quality to allow for prediction of microbiological or sensory quality and shelf-life of commercially HTST pasteurized fluid milk.

Although the analyses evaluating correlations between raw milk tests and pasteurized fluid milk quality parameters, excluding fluid milk with apparent spoilage by PPC, should provide for an appropriate evaluation of the ability of raw milk tests to predict effects of raw milk quality parameters on HTST fluid milk quality and shelf-life, these data do not exclude the possibility that processing plant-specific parameters and factors might obscure correlations between raw milk quality parameters and pasteurized fluid milk quality. To address this issue, all raw milk samples were subjected to laboratory pasteurization [i.e., batch treatment at $63^{\circ} \mathrm{C}$ $\left(145^{\circ} \mathrm{F}\right)$ for $\left.30 \mathrm{~min}\right]$, followed by incubation at $6^{\circ} \mathrm{C}$ over $21 \mathrm{~d}$, with bacterial enumeration on SPC agar on d 0, 7, 10, 14, 17, and 21 (i.e., an LPC). This laboratory treatment, which is also known as batch pasteurization, provides a level of human pathogen inactivation in raw milk that is equivalent to that of HTST pasteurization (FDA, 2009). We reasoned that, due to our ability to control PPC in the laboratory, as well as other possible confounding factors (i.e., differences in pasteurization temperature among plants; Ranieri et al., 2009), the LPC provides a close approximation of the quality of pasteurized milk under conditions when all plant factors could be controlled. Correlations between different raw milk test results and d 17 LPC ranged from 0.0002 (for SP) to 0.0907 (for CVTA); correlations between raw milk test results and d 21 LP were similarly low, ranging from $R^{2}$ values of 0.0003 (for PI, see Figure 2c) to 0.0798 (for PBC) (Table 2). These results further support that none of the raw milk tests evaluated here show appropriate relationships with pasteurized product quality to justify their use to predict the quality of pasteurized product produced from a given silo tank of raw milk.

Although it may be tempting to propose that a raw milk test that showed, by relative comparison, the best correlation with pasteurized milk quality be used as an indicator of pasteurized milk quality (e.g., CVTA, see Table 2), it is important to emphasize that none of the raw milk tests evaluated showed $R^{2}$ values of $>0.45$, suggesting that none of these tests have predictive power. In biological systems, an $\mathrm{R}^{2}$ value of at least 0.50 to 0.80 is needed to indicate a strong relationship between tests (Trigiano and Gray, 1999). In addition to statistically significant relationships between raw milk tests and pasteurized milk quality, the strength of biological relationships between organisms detected by a raw milk test and pasteurized milk spoilage should also be considered. For example, plating on CVTA predominantly detects gram-negative organisms (e.g., Aeromonas spp., Klebsiella spp.) that are easily inactivated by HTST pasteurization; hence, no clear biological link exists between raw milk bacterial counts on CVTA and HTST milk spoilage.

Our data convincingly demonstrate that raw milk tests do not predict the sensory and microbiological shelf-life of HTST pasteurized milk; however, it is important to consider that the overall quality of the raw milk evaluated here was good (e.g., average SPC of 
Table 3. Selected raw milk and finished product parameters for individual pairs of raw and pasteurized milk samples collected from 4 New York State processing plants over a 1-yr period

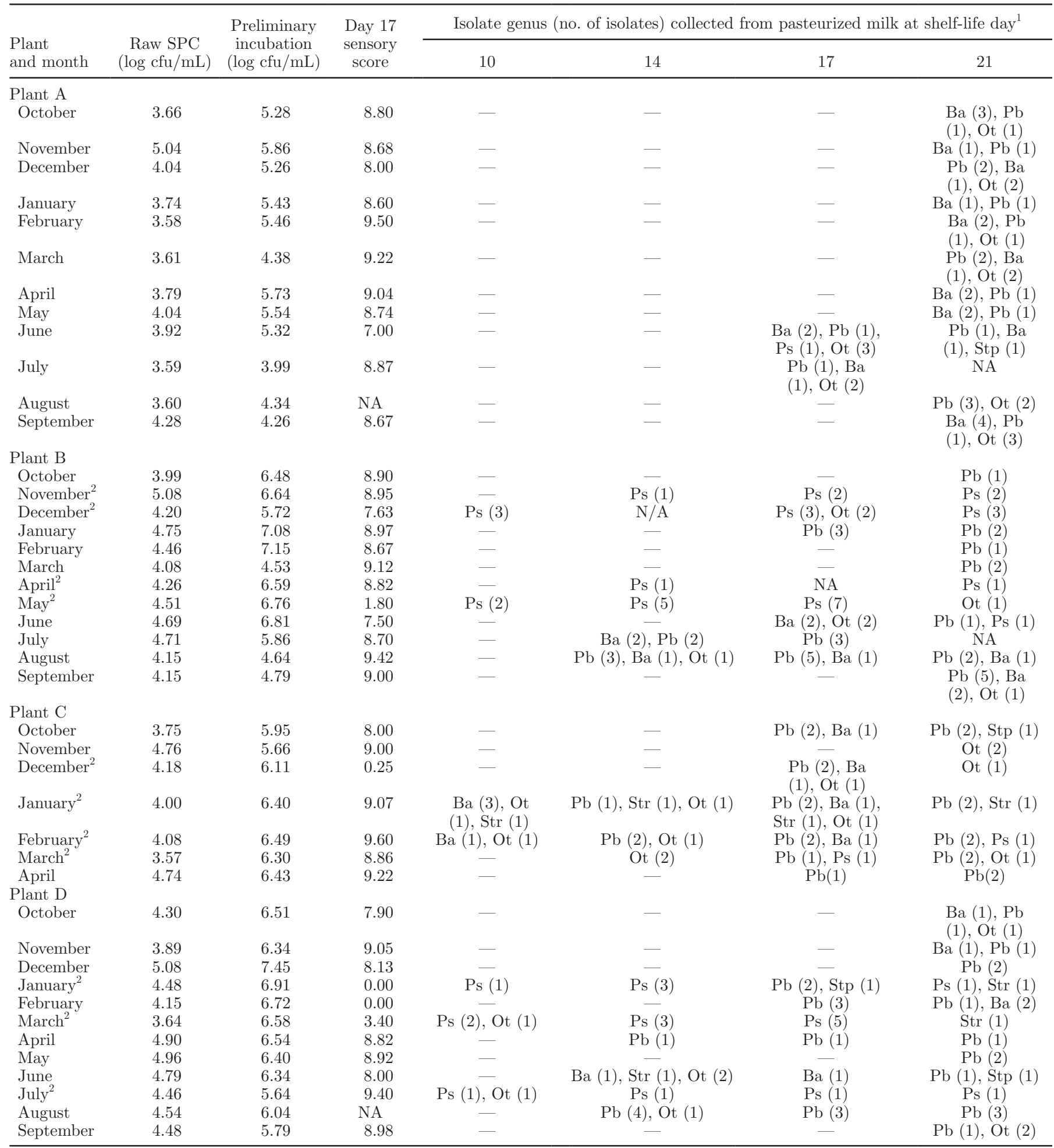

${ }^{1}$ These columns list the genus of bacterial isolates collected from pasteurized milk samples tested at shelf-life life $\mathrm{d} 10,14,17$, and 21 ; isolates were collected and identified by $16 \mathrm{~S}$ sequencing from samples that showed $\mathrm{SPC}>20,000 \mathrm{cfu} / \mathrm{mL}$ and from all d 21 samples; $-=$ samples for which no isolates were collected; NA = samples that met inclusion criteria but for which isolates were not available for characterization. Isolates were characterized into the genera Pseudomonas (Ps), Streptococcus (Str), Bacillus (Ba), Staphylococcus (Stp), Paenibacillus (Pb); genera that were rarely isolated are listed as Others (Ot).

${ }^{2}$ Indicates sample pairs where the pasteurized milk samples showed microbiological evidence for post-pasteurization contamination. 
$18,000 \mathrm{cfu} / \mathrm{mL}$, range 3,700-120,000 $\mathrm{cfu} / \mathrm{mL}$; average SCC of 220,000 cells/mL, range 160,000-280,000 cells/ $\mathrm{mL})$. Many of the tests evaluated here are appropriate for screening for overall poor quality milk, including use in troubleshooting on-farm milk quality problems, even if they do not accurately and reproducibly predict finished product quality when applied to commingled milk.

\section{Plant Factors Appear to Have a Major Effect on Pasteurized Milk Quality}

Our data also suggest that plant-specific and in-plant factors have important effects on pasteurized milk quality. As detailed above, one key factor contributing to the quality of commercially produced HTST milk is PPC; not only did 11 of the 43 pasteurized milk samples show evidence for PPC, occurrence of PPC also differed among plants, with only plant A showing no evidence of PPC among all samples tested. Overall, these findings are consistent with previous studies suggesting that PPC is still a major cause of pasteurized HTST product spoilage across the United States (Ralyea et al., 1998; Dogan and Boor, 2003; Carey et al., 2005; Ranieri and Boor, 2009; Ranieri et al., 2009).

In addition to PPC, other plant factors that affect pasteurized milk quality include pasteurization conditions. Ranieri et al. (2009) specifically showed, in controlled pilot-plant pasteurization trials, that pasteurization temperature is inversely related to bacterial growth over refrigerated product shelf-life (i.e., higher pasteurization temperatures lead to greater bacterial growth). This phenomenon is well correlated with outgrowth of grampositive psychrotolerant endospore-forming bacteria belonging to the genus Paenibacillus (Ralyea et al., 1998; Fromm and Boor, 2004; Huck et al., 2007b; Ranieri and Boor, 2009). The growth of these microbes appears to be enhanced in milk that is pasteurized at higher relative temperatures $\left(>75^{\circ} \mathrm{C}\right)$, possibly due to greater inactivation of endogenous antimicrobial systems (e.g., the lactoperoxidase system) or enhanced germination of the spores that are present in the raw milk. Interestingly, our data on commercially processed HTST milks are consistent with the findings from the pilot-plant study reported by Ranieri et al. (2009). Specifically, HTST milk samples from plant A, which had the lowest pasteurization temperature, showed the lowest average bacterial numbers after $17 \mathrm{~d}$ of refrigerated storage, whereas milk from all other plants showed, on average, at least $2 \log$ (100-fold) higher bacterial numbers at d 17 (Table 1, Figure 3). Importantly, though, none of the pasteurized milk samples from plant A showed evidence of PPC, suggesting that, in general, plant A represents a facility with a high level of quality control.
Hence, an overall high level of quality control may also be responsible for, or contributing to, the high quality finished product. The importance of plant-specific factors for HTST product quality is also supported by the fact that, despite a wide range of microbial quality of commercially pasteurized milk among the samples collected during this study (Figure 3), the LP counts after $17 \mathrm{~d}$ were generally $<20,000 \mathrm{cfu} / \mathrm{mL}$ and were not significantly different among the raw milk that had been collected at the different plants (see Figure 3), indicating that raw milk sampled from all plants was capable of performing well under refrigerated storage, following pasteurization.

\section{CONCLUSIONS}

Our results indicate that none of the tests commonly used by the fluid milk industry to screen raw milk have the ability to predict the bacterial or sensory quality of pasteurized milk. As plant factors such as PPC have a major role in determining the quality of pasteurized milk produced in many plants, further efforts to optimize in-plant quality assurance and contamination control will be critical to further improve fluid milk quality and shelf-life. Nevertheless, it is apparent that milk contamination with spore-forming bacteria, in particular Paenibacillus spp., and outgrowth of these bacteria at refrigeration temperatures represent major factors limiting product shelf-life to approximately $21 \mathrm{~d}$, when PPC is controlled (Huck et al., 2007a,b; Ranieri and Boor, 2009; Ranieri et al., 2009). Although raw milk tests are available that specifically enumerate spores in raw milk (i.e., SP, which involves enumeration of bacteria present after a heat treatment that kills most non-spore-forming bacteria), we found that SP counts also did not correlate with fluid milk spoilage. This finding is not as surprising as it may initially seem, because raw milk can contain heat-resistant bacterial spores representing different genera, including Bacillus spp. and Paenibacillus spp. (Ralyea et al., 1998; Fromm and Boor, 2004; Huck et al., 2007b; Ranieri and Boor, 2009). Although many vegetative Bacillus spp. cells do not typically grow under refrigeration temperatures, a considerable proportion of Paenibacillus spp. appear to have the ability to grow in milk under refrigeration temperatures, although typically at growth rates lower than that of Pseudomonas spp. (Fromm and Boor, 2004). Initial loads of spore-formers in raw milk (and in particular Paenibacillus spp.) are often very low and below the SP detection limit. The SP test thus lacks the sensitivity and specificity needed to detect the spore-forming bacteria likely to affect fluid milk shelflife. We conclude that the dairy industry is still in need of a scientifically valid raw milk test that will be able 

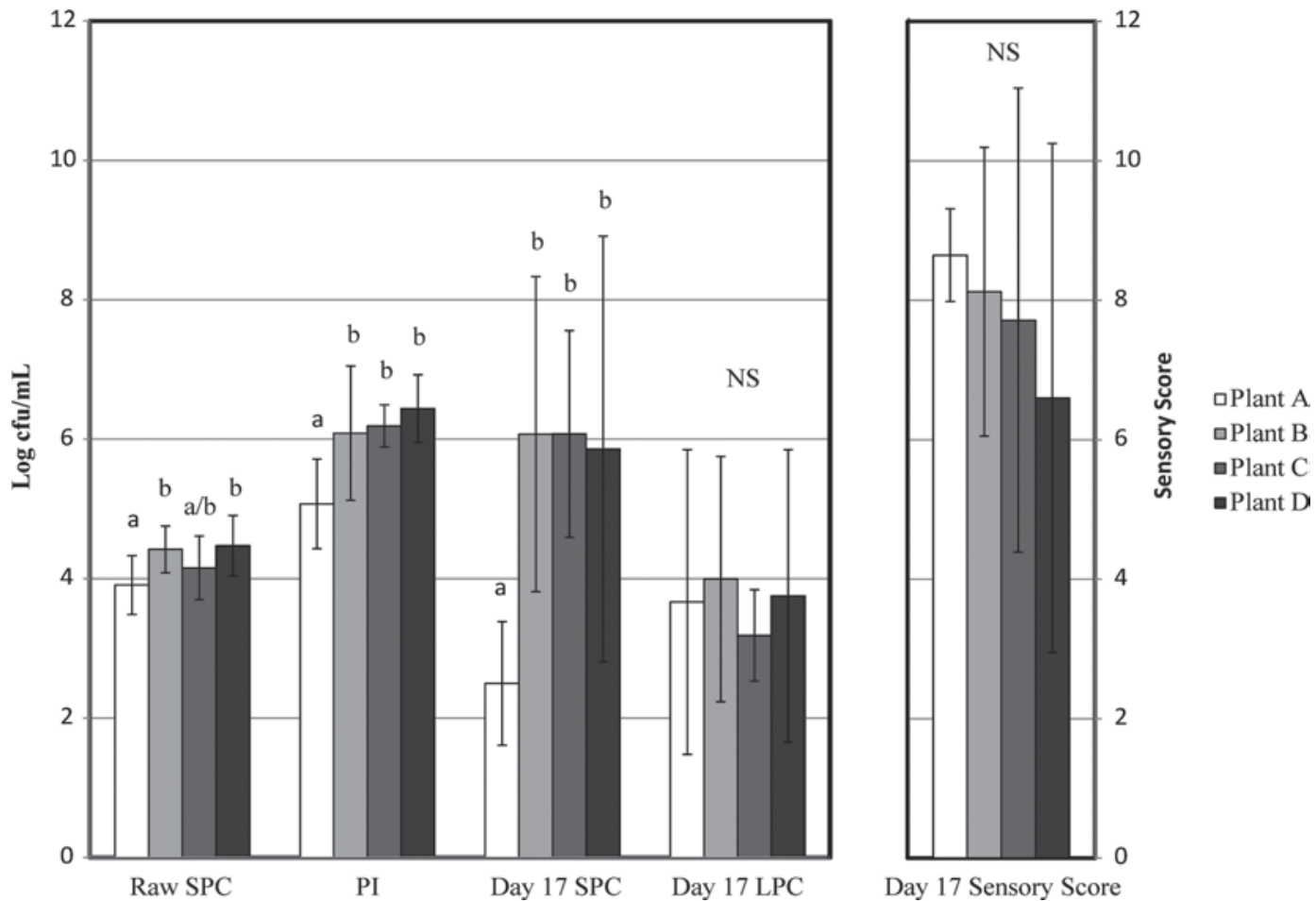

Figure 3. Selected mean raw milk and mean pasteurized milk quality parameters for samples collected from 4 New York State fluid milk processors. Raw milk quality parameters shown include log-transformed mean SPC and preliminary incubation (PI) counts; quality parameters shown for pasteurized $2 \%$ milk include mean log-transformed d 17 SPC and mean sensory scores. Mean d 17 laboratory pasteurization count (LPC) data are also shown. Data represent the means for 12 samples (plants A, B, and D) and 7 samples (plant C); error bars represent \pm 1 SD. Different letters within a parameter indicate a significant difference.

to predict the quality and shelf-life of pasteurized milk, with the implicit understanding that raw milk tests will only be able to predict pasteurized milk shelf-life and quality if absence of PPC can be assured. Future research is also needed to further evaluate the correlation between HTST product quality and different raw milk tests when applied to individual bulk tank milk samples rather than commingled samples.

\section{ACKNOWLEDGMENTS}

This project was supported by the New York State Milk Promotion Advisory Board through the New York State Department of Agriculture and Markets-New York State dairy farmers committed to production of high quality dairy products. The authors thank the technical staff of the Milk Quality Improvement Program (Cornell University, Ithaca, NY) as well as the New York State milk processing facilities that participated in this study for their assistance.

\section{REFERENCES}

Adams, D. M., J. T. Barach, and M. L. Speck. 1976. Effect of psychrotrophic bacteria from raw milk on milk proteins and stability of milk proteins to ultrahigh temperature treatment. J. Dairy Sci. 59:823-827.

Barbano, D. M., Y. Ma, and M. V. Santos. 2006. Influence of raw milk quality on fluid milk shelf life. J. Dairy Sci. 89(E. Suppl.):E15E19.

Bodyfelt, F. W., J. Tobias, and G. M. Trout. 1988. The Sensory Evaluation of Dairy Products. Van Nostrand Reinhold, New York, NY.

Boor, K. J., D. P. Brown, S. C. Murphy, S. M. Kozlowski, and D. K. Bandler. 1998. Microbiological and chemical quality of raw milk in New York State. J. Dairy Sci. 81:1743-1748.

Carey, N. R., S. C. Murphy, R. N. Zadoks, and K. J. Boor. 2005. Shelf-lives of pasteurized fluid milk products in New York State: A ten-year study. Food Prot. Trends 25:102-113.

Collins, E. B. 1981. Heat resistant psychrotrophic microorganisms. J. Dairy Sci. 64:157-160.

Dogan, B., and K. J. Boor. 2003. Genetic diversity and spoilage potentials among Pseudomonas spp. isolated from fluid milk products and dairy processing plants. Appl. Environ. Microbiol. 69:130138

Duncan, D. E., B. R. Yaun, and S. S. Sumner. 2004. Microbiological methods for dairy products. 249-268 in Standard Methods for the Examination of Dairy Products. 17th ed. H. M. Wehr and J. F. Frank, ed. Am. Public Health Assoc., Washington, DC.

FDA. 2009. Standards for grade "A" milk and milk products. Pages 28-31 in Grade "A" Pasteurized Milk Ordinance. US Department of Health and Human Services, Public Health Service, Washington, DC.

Frank, J. F., and A. E. Yousef. 2004. Tests for groups of microorganisms. Pages 227-248 in Standard Methods for the Examination of Dairy Products. 17th ed. H. M. Wehr and J. F. Frank, ed. Am. Public Health Assoc., Washington, DC.

Fromm, H. I., and K. J. Boor. 2004. Characterization of pasteurized fluid milk shelf-life attributes. J. Food Sci. 69:207-214. 
Grieve, P. A., and B. J. Kitchen. 1985. Proteolysis in milk: The significance of proteinases originating from milk leucocytes and a comparison of the action of leucocyte, bacterial and natural milk proteinases on casein. J. Dairy Res. 52:101-112.

Huck, J. R., B. H. Hammond, S. C. Murphy, N. H. Woodcock, and K. J. Boor. 2007b. Tracking spore-forming bacterial contaminants in fluid milk-processing systems. J. Dairy Sci. 90:4872-4883.

Huck, J. R., N. H. Woodcock, R. D. Ralyea, and K. J. Boor. 2007a. Molecular subtyping and characterization of psychrotolerant endospore-forming bacteria in two New York State fluid milk processing systems. J. Food Prot. 70:2354-2364.

Jayarao, B. M., and L. Wang. 1999. A study on the prevalence of gramnegative bacteria in bulk tank milk. J. Dairy Sci. 82:2620-2624.

Johns, C. K., and G. B. Landerkin. 1969. Effects of preliminary incubation on the bacterial flora of bulk-tank milks produced in three different Canadian milk sheds. J. Dairy Sci. 52:1935-1940.

Klei, L., J. Yun, A. Sapru, J. Lynch, D. Barbano, P. Sears, and D. Galton. 1998. Effects of milk somatic cell count on cottage cheese yield and quality. J. Dairy Sci. 81:1205-1213.

Laird, D. T., A. Gambrel-Lenarz, F. M. Scher, T. E. Graham, and R. Reddy. 2004. Microbiological count methods. 153-186 in Standard Methods for the Examination of Dairy Products. 17th ed. H. M. Wehr and J. F. Frank, ed. Am. Public Health Assoc., Washington, DC.

Ma, Y., C. Ryan, D. M. Barbano, D. M. Galton, M. A. Rudan, and K. J. Boor. 2000. Effects of somatic cell count on quality and shelf-life of pasteurized fluid milk. J. Dairy Sci. 83:264-274.

Murphy, S. C. 2008. The preliminary incubation count for raw milk: An old test revisited. Dairy Foods Science Notes. Milk Quality Improvement Program, Cornell University Department of Food Science, Ithaca, NY.
Politis, I., and K. F. Ng-Kwai-Hang. 1988. Effects of somatic cell counts and milk composition on cheese composition and coagulating properties of milk. J. Dairy Sci. 71:1711-1719.

Ralyea, R. D., M. Wiedmann, and K. J. Boor. 1998. Bacterial tracking in a dairy production system using phenotypic and ribotyping methods. J. Food Prot. 61:1336-1340.

Ranieri, M. L., and K. J. Boor. 2009. Short communication: Bacterial ecology of high-temperature, short-time pasteurized milk processed in the United States. J. Dairy Sci. 92:4833-4840.

Ranieri, M. L., J. R. Huck, M. Sonnen, D. M. Barbano, and K. J. Boor. 2009. High temperature, short time pasteurization temperatures inversely affect bacterial numbers during refrigerated storage of pasteurized fluid milk. J. Dairy Sci. 92:4823-4832.

Reneau, J. K. 2007. 100,000 SCC: Why not? Presented at the University of Minnesota Dairy Days. Accessed September 1, 2010. http:// www.thecattlesite.com/articles/1191/100000-scc-why-not.

Trigiano, R. N., and D. J. Gray. 1999. Plant Tissue Culture Concepts and Laboratory Exercises. 2nd ed. CRC Press LLC, Boca Raton, FL

Wilson, J. 2002. A coops perspective on milk quality. DeLaval Hygiene Symposium and R\&D Center Inaugural. Accessed September 1, 2010. http://www.milkproduction.com/NR/rdonlyres/ 2CD4DB7D-D7BB-4C0B-9317-70707BC3FFE9/0/A.pdf.

Worster, A., J. Fan, and A. Ismaila. 2007. Understanding linear and logistic regression analyses. CJEM 9:111-113.

Zadoks, R. N., R. N. Gonzalez, K. J. Boor, and Y. H. Schukken. 2004. Mastitis-causing streptococci are important contributors to bacterial counts in raw bulk tank milk. J. Food Prot. 67:2644-2650.

Zimbro, M. J., D. A. Power, S. M. Miller, G. E. Wilson, and J. A Johnson. 2009. Difco \& BBL Manual. Manual of Microbiological Culture Media. 2nd ed. Becton Dickinson and Co., Sparks, MD. 